Research Article

\title{
Gene expression analysis reveals important pathways for drought response in leaves and roots of a wheat cultivar adapted to rainfed cropping in the Cerrado Biome
}

\author{
Liane Balvedi Poersch-Bortolon ${ }^{1}$, Jorge Fernando Pereira ${ }^{2}$, Antonio Nhani Junior ${ }^{2}$, \\ Hebert Hernán Soto Gonzáles ${ }^{2,3}$, Gisele Abigail Montan Torres ${ }^{2}$, Luciano Consoli ${ }^{2}$, \\ Rafael Augusto Arenhart ${ }^{1}$, Maria Helena Bodanese-Zanettini ${ }^{1}$ and Márcia Margis-Pinheiro ${ }^{1}$ \\ ${ }^{1}$ Departamento de Genética, Instituto de Biociências, Universidade Federal do Rio Grande do Sul, \\ Porto Alegre, RS, Brazil. \\ ${ }^{2}$ Embrapa Trigo, Passo Fundo, RS, Brazil. \\ ${ }^{3}$ Programa de Pós-Graduação em Recursos Naturais, Universidade Federal de Roraima, \\ Boa Vista, RR, Brazil.
}

\begin{abstract}
Drought limits wheat production in the Brazilian Cerrado biome. In order to search for candidate genes associated to the response to water deficit, we analyzed the gene expression profiles, under severe drought stress, in roots and leaves of the cultivar MGS1 Aliança, a well-adapted cultivar to the Cerrado. A set of 4,422 candidate genes was found in roots and leaves. The number of down-regulated transcripts in roots was higher than the up-regulated transcripts, while the opposite occurred in leaves. The number of common transcripts between the two tissues was 1,249 , while 2,124 were specific to roots and 1,049 specific to leaves. Quantitative RT-PCR analysis revealed a 0.78 correlation with the expression data. The candidate genes were distributed across all chromosomes and component genomes, but a greater number was mapped on the B genome, particularly on chromosomes 3B, 5B and $2 \mathrm{~B}$. When considering both tissues, 116 different pathways were induced. One common pathway, among the top three activated pathways in both tissues, was starch and sucrose metabolism. These results pave the way for future marker development and selection of important genes and are useful for understanding the metabolic pathways involved in wheat drought response.
\end{abstract}

Keywords: 454 sequencing, candidate genes, RT-qPCR, Triticum aestivum, water deficit.

Received: December 22, 2015; Accepted: June 27, 2016.

\section{Introduction}

The central part of Brazil, consisting mostly of the Cerrado biome, is considered to be the new frontier for increasing Brazilian wheat production. Although the wheat harvest in that region can reach more than 4,000 kg.ha ${ }^{-1}$ on average in irrigated areas (De Mori and Só e Silva, 2013), rainfed cropping has great potential to improve production once it requires little investment and has a large area for expansion. To follow this path, rainfed wheat production in the Brazilian Cerrado must cope with three major abiotic stresses: soil acidity, heat and drought (Scheeren et al., 2008).

Drought is broadly accepted as the most important environmental stress in agriculture and is a major constraint

Send correspondence to Jorge Fernando Pereira. Embrapa Trigo, Laboratório de Biotecnologia, Rodovia BR-285 Km 294, Caixa Postal 3081, 99050-970, Passo Fundo, RS, Brazil. E-mail: jorge.pereira@embrapa.br on plant survival, productivity and quality (Nezhadahmadi et al., 2013). Drought is forecast to be exacerbated by incremental increases in temperature and changes in precipitation profiles. For instance, each degree ${ }^{\circ} \mathrm{C}$ of increase in global mean temperature is projected to reduce global wheat grain production by approximately $6 \%$ (Asseng $e t$ al., 2015). In Brazil, wheat yield is theorized to be reduced up to $31 \%$ with temperature increases of $3-4{ }^{\circ} \mathrm{C}$, offsetting the positive effects of increased $\mathrm{CO}_{2}$ levels on wheat grain yield (Siqueira et al., 2000; Streck and Alberto, 2006). Because water is largely used in irrigated agriculture ( $70-90 \%$ of global water use), this sector will be heavily affected by climate change (Bär et al., 2015). In this context, improving drought tolerance of wheat cultivars is essential for yield increases in rainfed farming.

Plants have developed several mechanisms to address drought stress, and drought tolerance is a quantitative trait with a complex response at molecular, metabolic and physiological levels (Nezhadahmadi et al., 2013). In wheat, sev- 
eral traits, such as the timing of phenological stages, carbohydrate metabolism, stomatal conductance, osmotic adjustment, late senescence of the flag leaf, flowering time, increased root:shoot ratio, high values of soluble stem carbohydrate shortly after anthesis, and increased early ground cover, among others, have been linked to the drought tolerance response (Fischer et al., 1998; Foulkes et al., 2007; Reynolds et al., 2007; Nezhadahmadi et al., 2013). To understand the mechanisms underlying this response, gene expression analysis using subtractive cDNA libraries and microarrays have been performed in wheat (Zhang et al., 2004; Way et al., 2005; Xue et al., 2006, 2008; Mohammadi et al., 2008; Ergen et al., 2009; Li et al., 2012; Reddy et al., 2014). However, nowadays, the most preferred technique to evaluate gene expression is high-throughput cDNA sequencing (RNA-Seq) based on next-generation sequencing technology. Up till now, the use of RNA-seq, which is not limited to the number of transcripts predefined in probes, to study the drought response in bread wheat (Triticum aestivum) has been rare (Okay et al., 2014; Liu et al., 2015; Budak et al., 2015). One obstacle to that type of study in bread wheat is the complexity of its hexaploid genome, which is estimated to be 17 gigabases in size and encoding more than 124,000 genes, of which approximately $76 \%$ of the assembled sequences contain repeats (IWGSC- International Wheat Genome Sequencing Consortium, 2014).

In the present study, a gene expression analysis was performed aiming at the identification of candidate genes involved in the drought responses in a wheat cultivar adapted to the Brazilian Cerrado region. A set of 4,422 candidate genes was obtained, with 2,124 specific to roots, 1,049 specific to leaves, and 1,249 sequences that were common between both tissues. A strong correlation between RNA-seq and RT-qPCR (quantitative reverse transcription polymerase chain reaction) data was observed. The importance of specific chromosome regions and genomes, as well as the most activated pathways, are reported. These results are also applied to the understanding of the metabolic pathways involved in wheat drought response.

\section{Materials and Methods}

\section{Plant material, drought stress and RNA extraction}

The Brazilian wheat cultivar MGS1 Aliança (Triticum aestivum) was used in this study due its good productivity in rainfed farming in the Brazilian Cerrado. This cultivar showed the highest yield across different sowing dates among 152 wheat genotypes tested under drought conditions in the Cerrado (Ribeiro Júnior et al., 2006). MGS1 Aliança was released in 1990 by EPAMIG (Empresa de Pesquisa Agropecuária de Minas Gerais) and it is still recommended for wheat production in the Cerrado (Comissão Brasileira de Pesquisa de Trigo e Triticale (2016). Seeds of MGS1 Aliança were surface-sterilized in
$\mathrm{NaClO}(0.2 \%$ of active chlorine) for $1 \mathrm{~min}$, washed three times with sterile distilled water (1 min each) and germinated at $23{ }^{\circ} \mathrm{C}$ in the dark for two days. Germinated seeds were transferred to pots ( 3 seeds per pot) containing $6.5 \mathrm{~kg}$ of a mixture of soil, sand and vermiculite (2:1:1) and incubated in a glasshouse with natural light at $22 \pm 4{ }^{\circ} \mathrm{C}$. Plants were watered daily. Control plants were grown for five weeks at $100 \%$ of field capacity while, in the stress treatment, plants were watered for 2 weeks at $75 \%$ of field capacity followed by 3 weeks of water deprivation. The water status of the plants was monitored by measurement of the leaf relative water content (RWC) (Barrs and Weatherley, 1962) and the water potential (Scholander pump). All three plants from one pot were pooled and the leaves and roots were collected separately, immediately frozen in liquid nitrogen, and stored at $-80^{\circ} \mathrm{C}$. Total RNA was extracted with TRIzol ${ }^{\circledR}$ reagent (Invitrogen) according to the manufacturer's instructions, and purified using an RNeasy Mini Kit (Qiagen). During the purification, a DNase digestion step was performed with an RNase-free DNase Set (Qiagen). RNA quality was assessed using a Bioanalyzer (Agilent) and samples with an RIN (RNA integrity number) $>7.5$ and rRNA ratio $>1.5$ were used in subsequent analyses.

\section{Sequencing}

Total RNA was sent to Macrogen Inc. (South Korea) for sequencing of four libraries (control root, treated root, control leaf, and treated leaf) on a Genome Sequencer FLX Titanium instrument (Roche) according to standard protocols.

\section{Sequence data analysis, de novo assembly and functional annotation}

The sequence data analysis, assembly and annotation followed the protocol available from Macrogen. Briefly, raw data were processed using the Roche GS FLX software v 2.8. The reads were assembled using GS De Novo Assembler software $v 2.6$. The assembly parameters were kept at default values for both the assembly and cDNA option. Singleton cleaning (elimination of contaminants, low quality, low-complexity and vectors) was performed in SeqClean (http://sourceforge.net/projects/seqclean/), with a minimum length of $100 \mathrm{bp}$ and Lucy (http://lucy.sourceforge.net/). Similarity analysis was performed using BLAST (1.0e-3 cutoff) and the Gene Ontology (GO) (http://www.geneontology.org/) database to obtain sequence annotations. The data discussed in this study have been deposited in NCBI Gene Expression Omnibus (Edgar et al., 2002) and are accessible through GEO Series accession number GSE1833 (www.ncbi.nlm.nih.gov/geo).

\section{Statistical analysis}

Statistical analyses of differentially expressed transcripts between the control and stressed treatments were 
performed with the DEGseq $\mathrm{v} 22.6 \mathrm{R}$ package (http://www.bioconductor.org/packages/2.6/bioc/html/

DEGseq.html), using the MARS model. Isotigs with a p-value $<0.001$ were considered significantly different. The compared samples were: control leaf assembled sequences (isotigs) versus drought-stressed leaf assembled sequences (isotigs), and control root assembled sequences (isotigs) versus drought-stressed root assembled sequences (isotigs).

\section{CAP3 assembly, Blast2GO, genome assembly and functional annotation}

A second round of assembly was performed with two aims: (1) to group sequences lacking previous significant identity that could belong to the same transcript but may have come from different genomic regions; and (2) to compare the expression of transcripts in each tissue (leaf and root). All the isotigs and singleton sequences from roots and leaves, as well as the quality sequence files, were used as input. The analysis was performed with CAP3 (Huang and Madan, 1999) software using default parameters, except for a 40 overlap length cutoff and a 90 overlap percent identity cutoff. Assembled sequences that contained one or more differentially expressed transcript in their composition and had previously been determined (by DEGseq) were considered as differentially expressed (DE) as well. These DE sequences (contigs and singletons) from CAP3 assembly were annotated using Blast2GO software (Götz et al., 2008) with default parameters. Blast2GO performs searches against the Gene Ontology (GO), the Kyoto Encyclopedia of Genes and Genomes (KEGG) and Interpro databases in order to determine the metabolic pathways they belong to. After annotation, the sequences obtained from the Cap3 assembly were mapped against the available Ensembl genomic sequences of Triticum aestivum (v. 1.26; http://plants.ensembl.org/Triticum_aestivum/Info/Index) using BWA (Li and Durbin, 2010) and SAMtools (Li et al., 2009) to analyze the distribution of these sequences over the wheat chromosomes and genomes. Mapping was carried out using BWA-SW "-t 6" or 6 threads. A chi-square test was used to determine if the distribution among the $T$. aestivum component genomes was statistically different. To identify transcriptions factors (TFs) encoding transcripts among the genes differentially expressed under drought, the sequences were compared by similarity search (BlastP cutoff 1e-100) against the Plant Transcription Factor Database version 3.0 (PlantTFDB) (http://www.bmicc.org/web/english/search/planttfdb) (Jin et al., 2014).

\section{RT-qPCR}

Drought stress treatment was similar to the procedure described previously, except that five plants were cultivated per pot and incubated in a growth cabinet with controlled conditions $\left(22{ }^{\circ} \mathrm{C}\right.$ with $16 / 8$ hours light/dark and humidity at $60 \%$ ). Root and leaf samples, from a pool of five plants belonging to the same pot, were collected at two time points: after two weeks of growth and after five weeks of growth. The experiment was performed in triplicate biological samples. RNA extraction and purification were performed as described above. RNA quality and quantity were assessed using a NanoDrop 2000 Spectrophotometer (Thermo Scientific) and 1.5\% agarose gels. Synthesis of cDNA was done with the Thermo ScriptTM RT-PCR System (Invitrogen) using $2 \mu \mathrm{g}$ of DNA-free RNA and Oligo $(\mathrm{dT})_{20}$ primers. Gene-specific primers were designed using Primer3Plus (http://www.bioinformatics.nl/cgi-bin/ primer3plus/primer3plus.cgi/). RT-qPCR assays were conducted in technical triplicates using a 7500 Real Time PCR System (Applied Biosystems) with 7500 Software v2.0.6. The cycles and reactions were as follows: $10 \mathrm{~min}$ at $95^{\circ} \mathrm{C}$, followed by 40 cycles for $15 \mathrm{~s}$ at $95^{\circ} \mathrm{C}, 30 \mathrm{~s}$ at $60^{\circ} \mathrm{C}, 30 \mathrm{~s}$ at $72{ }^{\circ} \mathrm{C}$, and a final melting curve analysis protocol consisting of heating to $95^{\circ} \mathrm{C}$ for $15 \mathrm{~s}, 60^{\circ} \mathrm{C}$ for $1 \mathrm{~min}$ and heating to $95{ }^{\circ} \mathrm{C}$. Reactions were performed in a final volume of $25 \mu \mathrm{L}$, containing $12.5 \mu \mathrm{L}$ of $\mathrm{SYBR}^{\circledR}$ Green PCR Master Mix (Applied Biosystems), $10 \mu \mathrm{L}$ of diluted cDNA (1:100), $0.25 \mu \mathrm{L}$ of primers (10 $\mu \mathrm{M}$ each) and $2.25 \mu \mathrm{L}$ of water. Relative expression data analyses were performed by comparative quantification of the amplified products using the $2^{-\Delta \Delta \mathrm{CT}}$ method (Schmittgen and Livak, 2008). The reference genes used for normalization of expression were those encoding ATPase, Ribosylation Factor, RNAseL (Paolacci et al., 2009), Ta10105, Ta14126 and Ta27922 (Long et al., 2010). The geNorm v3.5 software (http://medgen.ugent.be/ jvdesomp/genorm/) was used to select the two best reference genes for the respective experimental condition.

\section{Results}

\section{Sequencing analysis}

In order to search for candidate genes and metabolic pathways associated to drought stress in wheat, highthroughput sequencing was done using 454 sequencing technology with cDNA originating from drought-stressed and control roots and leaves. When harvested, the mean values for leaf water potential and for RWC were, respectively, $-0.38 \mathrm{MPa}$ and $98 \%$ in the control plants and $-2.12 \mathrm{MPa}$ and $50.1 \%$ in the stressed plants, indicating that, based on the parameters detailed by Hsiao (1973), the treated plants were severely drought-stressed. The sequencing analyses yielded 1,225,438 reads from the four libraries (control and treated roots, control and treated leaves). Among these, 305,731 reads were obtained for the root control sample and 300,578 for roots under drought stress. From the total 606,309 reads, 453,218 reads $(74.7 \%)$ were fully assembled and 32,085 isotigs were identified, with an average size of 1,085 bases and an N50 of 1,299. Fifteen percent $(90,933$ reads) were partially assembled, 
and $6.6 \%(40,377$ reads) remained as singletons, with 37,457 reads considered valid. Additionally, 17,257 reads were anchored to repeat regions, 4,179 were considered outliers and 345 were too short to be used in the computational analysis (Table 1).

Regarding the leaf-derived sequences, 619,131 reads were used in the assembly computation (319,997 from leaves in control sample and 299,134 from leaves under drought stress). From the total, 519,150 reads (83.8\%) were fully assembled and 19,899 isotigs were identified, with an average size of 952 bases and an N50 isotig size of 1,115. Approximately $10 \%$ of the reads $(65,475$ reads) were partially assembled and 5\% (31,374 reads) were singletons, with 28,880 reads considered valid. Furthermore, 189 reads anchored to repeat regions, 2,806 were considered outliers and 135 were too short to be used in the computational analysis (Table 1).

\section{Search for candidate genes}

After assembly and annotation, we searched for candidate genes differentially expressed between control and treated samples. The homogeneous distribution of the four libraries is presented in Figure S1. A total of 4,422 candidate genes was identified in both tissues $(p<0.001)$ (Table

Table 1 - Analyses of the reads obtained from the four libraries (root control, root stressed, leaf control, and leaf stressed)

\begin{tabular}{|c|c|c|}
\hline Reads & Root & Leaf \\
\hline Number of reads & 606,396 & 619,131 \\
\hline Number of bases & $366,686,703$ & $345,617,595$ \\
\hline Reads in control condition & 305,731 & 319,997 \\
\hline Number of bases in control condition & $184,485,642$ & $177,132,266$ \\
\hline Average read length & 603,425 & 553.544 \\
\hline Reads in drought condition & 300,665 & 299,134 \\
\hline Number of bases in drought condition & $182,201,061$ & $168,485,369$ \\
\hline Average read length & 605,994 & 563.244 \\
\hline Fully assembled & 453,218 & 519,150 \\
\hline Partially assembled & 90,933 & 65,475 \\
\hline Singletons & 40,377 & 31,374 \\
\hline Repeat & 17,257 & 189 \\
\hline Outlier & 4,179 & 2,806 \\
\hline Too short & 345 & 135 \\
\hline Number of isogroups & 24,900 & 16,585 \\
\hline Average contig count & 1.5 & 1.4 \\
\hline Number of isogroups with one isotig & 20,969 & 14,592 \\
\hline Number of isotigs & 32,085 & 19,899 \\
\hline Average isotig size & 1085,508 & 952.03 \\
\hline N50 isotig size & 1,299 & 1,115 \\
\hline Valid singletons & 37,457 & 28,880 \\
\hline
\end{tabular}

Isogroup is the collection of contigs containing reads that imply connections between them. Isotig is analogous to an individual transcript.
S1). Among those, 2,808 isotigs were obtained from roots, with 1,100 up-regulated and 1,708 down-regulated isotigs under stress conditions. Statistical analysis showed that 1,614 isotigs in leaves were significantly different ( $p$-value $<0.001)$. Up-regulation occurred in 1,017 isotigs, while down-regulation was observed in 597.

Gene Ontology (GO) categories of the candidate genes are shown in Figure 1. The functional annotation of the root and leaf isotigs revealed that $41 \%$ and $40 \%$ of the sequences were, respectively, involved in biological process, $25 \%$ and $24 \%$ in molecular function, $33 \%$ and $36 \%$ were cellular components, while the remaining sequences were no-hits. The comparison of GO terms among the four main categories revealed that the distribution of candidate genes was similar between root and leaf. Among the sequences annotated in biological processes, cellular and metabolic processes were highly represented. Among molecular functions, sequences related to binding and catalytic activity were the most represented GO terms. Regarding cellular component, the most represented category was cell part.

\section{Expression profile validation}

For validation of the gene expression analysis, a second and independent experiment was performed where plant samples were collected after two and five weeks of growth. For the two-week-old plants, mean leaf water potential and RWC values were $-0.37 \mathrm{MPa}$ and $96.7 \%$ for the control plants and $-0.39 \mathrm{MPa}$ and $95.8 \%$ for the treatment. After five weeks of growth, the mean values for leaf water potential and RWC were $-0.42 \mathrm{MPa}$ and $95.6 \%$ for the control plants and $-2.04 \mathrm{MPa}$ and $54.6 \%$ for the droughtstressed plants. This indicates that the plants had a similar water status before water was withheld but a different status after five weeks of growth. The analyses of the expression profile in two-week-old control (just before the irrigation withholding) as well as in five-week-old control and treated plants, allowed for the comparison of candidate gene expression not only after the drought period but also before the stress.

The relative expression of 15 root- and 20 leaf-derived transcripts (Table S2) was measured by RT-qPCR for experimental validation of the RNA-seq data. These 35 transcripts were chosen for validation because they showed different levels of expression (up- or down-regulated), are associated to different enzymes from the same pathway or belong to different metabolic pathways (Table S1). The expression of four root isotigs was not validated because the control and the drought-stressed samples after five weeks of growth were statistically similar. On the other hand, the expression of five root isotigs (R15, R24, R28, R36 and R22) were significantly different between treated and control plants after five weeks of growth (Figure 2A). When comparing the samples collected from two-week-old plants, only the R15 sequence was significantly different 


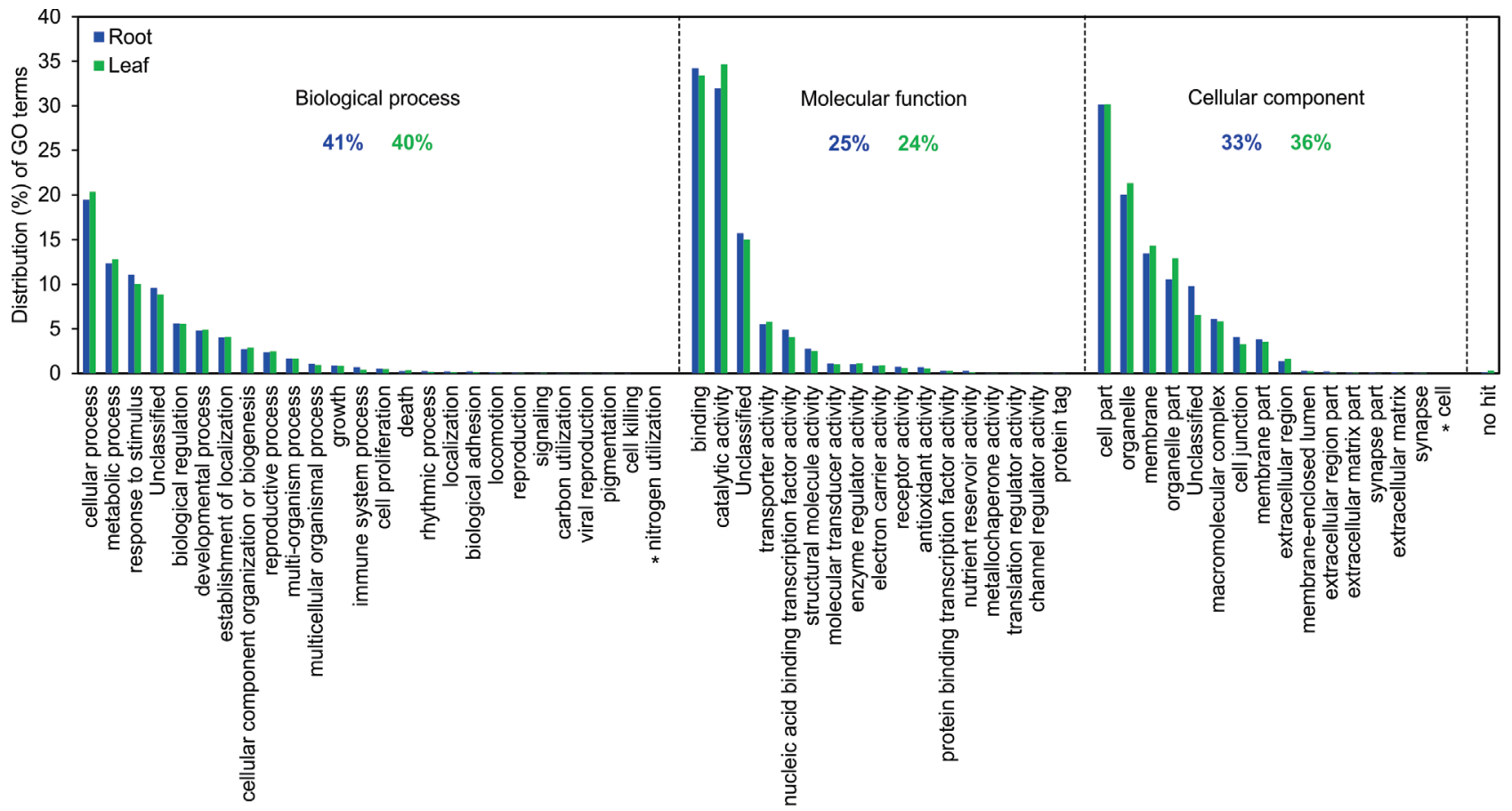

Figure 1 - Functional annotation of the 4,422 candidate genes detected in root and leaf tissues of the wheat cultivar MGS1 Aliança under drought stress. Gene Ontology (GO) analysis was performed for three main categories (biological process, molecular function and cellular component). Asterisk indicates GO terms present in root tissue only. No-hit sequences correspond to $0.1 \%$ and $0.3 \%$ of the leaf and root sequences, respectively. Note that a sequence may have multiples terms associated to it.

between treatments. For the other six isotigs, expression in control samples was not detected, but was detected in the drought-treated samples, indicating that their expression changed in response to water deprivation. Because of this change, the mean $\mathrm{Cq}$ values are presented (Figure 2B). A set of 20 transcripts from leaves was also evaluated by RT-qPCR. The expression of 12 isotigs (L1, L4, L8, L9, L10, L11, L15, L16, L17, L23, L25 and L29) were significantly different between the control and treated samples of five-week-old plants (Figure 3). Excluding the six root sequences with non-detected Cq values, the Pearson's correlation between the RNA-seq and RT-qPCR data for the other 29 transcripts was 0.78 (Figure S2).

\section{Genome localization and tissue-specificity of the candidate genes}

After comparing the candidate genes between root and leaf samples (2,808 and 1,614, respectively), 2,124 sequences were found to be specifically expressed in roots, 1,049 specifically in leaves, and 1,249 sequences were common to both tissues (Figure 4A). One sequence specific for each tissue (isotig06719, the same as the one used to design the primer R33 listed on Table S2), and isotig05306 (annotated as "AT1G47890 - defense response - kinase activity") for root and leaf, respectively, were used for RTqPCR analyses. The positive amplification of these sequences in specific tissues (Figure 4B) corroborates our in silico analysis. Searches against KEGG failed to detect pathways for these specific sequences.

An additional assembly (performed with the CAP3 software) allowed for the comparison of transcript expression between the two tissues. A total of 118,321 sequences were used (32,085 isotigs and 37,457 singletons from roots and 19,899 isotigs and 28,880 singletons from leaves). After the assembly, 11,746 contigs and 69,407 singlets were obtained with 1,393 and 2,594, respectively, considered as differentially expressed and, consequently, as candidate genes. The 3,987 candidate genes (1,393 contigs and 2,594 singlets) were analyzed for functional annotation, with $96.4 \%$ of sequences annotated and $4.5 \%$ showed mapping results (Figure S3). The highest similarity rate corresponded to sequences from Aegilops tauschii (30\%), followed by Hordeum vulgare (29.5\%), Triticum urartu (15\%), T. aestivum (13\%) and Brachypodium distachyon $(5.5 \%)$ (Figure $\mathrm{S} 3$ ). With regards to the GO distribution of the sequences assembled by CAP3 (Figure 5), the categories with the most abundant sequences in biological processes were metabolic processes, cellular processes, response to stimulus, single-organism processes, localization and biological regulation; for molecular function the most prevalent categories were catalytic activity and binding; and for cellular components the categories were cell, organelle and membrane.

To identify biological pathways that are active in wheat drought response, the 3,987 candidate genes de- 

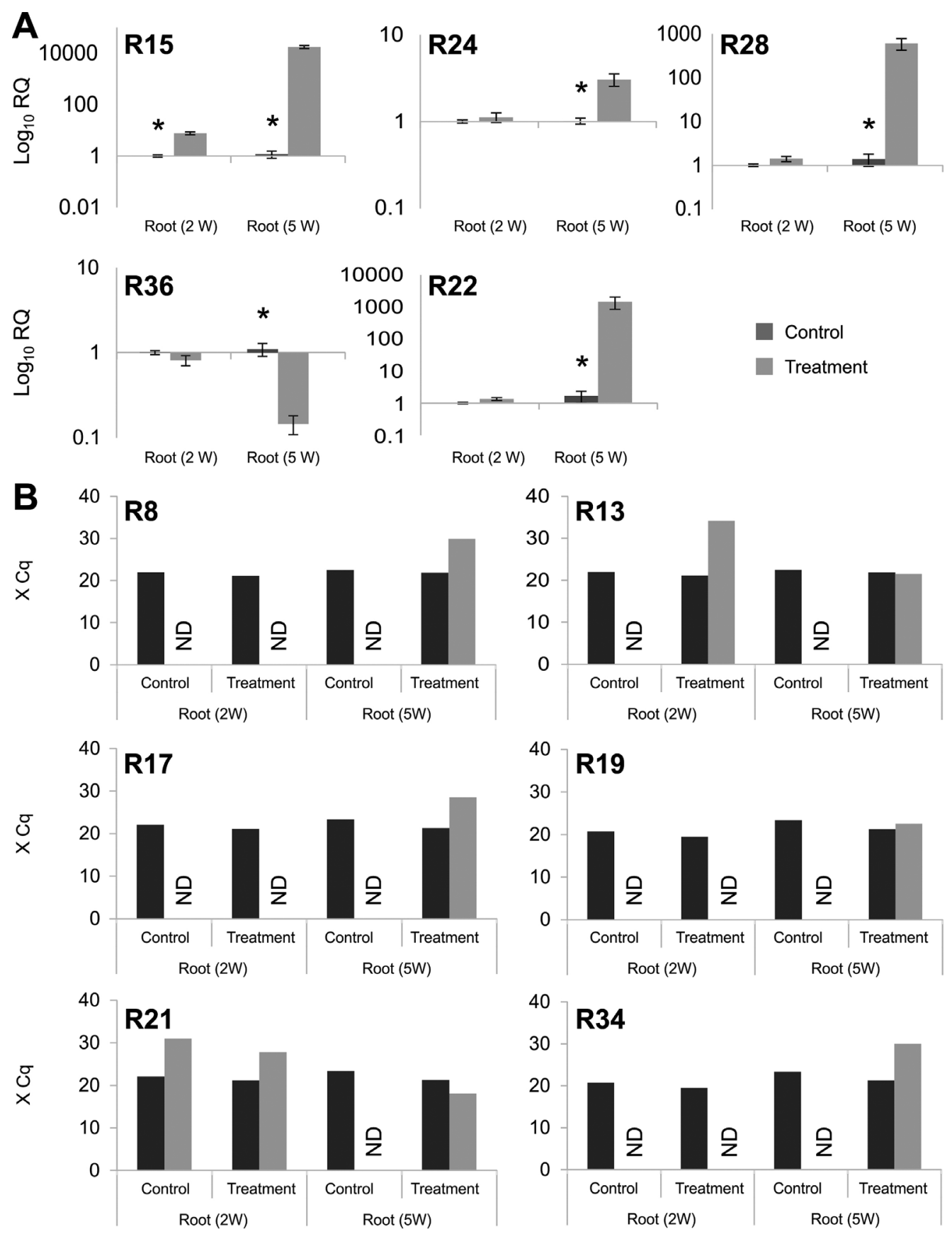

Reference gene

Isotig

Figure 2 - RT-qPCR analysis of selected root transcripts. Expression is shown for 11 transcripts that were validated by RT-qPCR. Wheat roots were sampled from two-week-old ( $2 \mathrm{~W}$ ) plants, where control plants were irrigated at $100 \%$ of field capacity (FC) and treated plants were irrigated at $75 \% \mathrm{FC}$. Five-week-old $(5 \mathrm{~W})$ plants are represented by control plants (irrigated at $100 \% \mathrm{FC}$ ) and treated plants, where irrigation was withdrawn for three weeks. The experiment was performed in triplicate biological samples and in technical triplicates. (A) Relative expression was calculated by the $2^{-\Delta \Delta c t}$ method. Asterisks represent significantly different (Student's $t$-test, $\mathrm{p} \leq 0.05$ ) transcript levels. (B) Mean of the Cq value. "ND" means not detected. For more details on primers see Table 2 and Table S2.

scribed above were analyzed using Blast2GO software against KEGG pathways. The results revealed 116 different pathways (Table S3) involved in wheat drought response. The top 20 pathways (with the highest number of sequences) for root and leaf tissues are presented in Figure 6.
Among the top 20 pathways in both tissues, 28 different pathways were detected, with 12 pathways in common but ranked in different positions. Starch and sucrose metabolism pathway-related transcripts had the highest ranking in roots but were the third most commonly identified ones in 

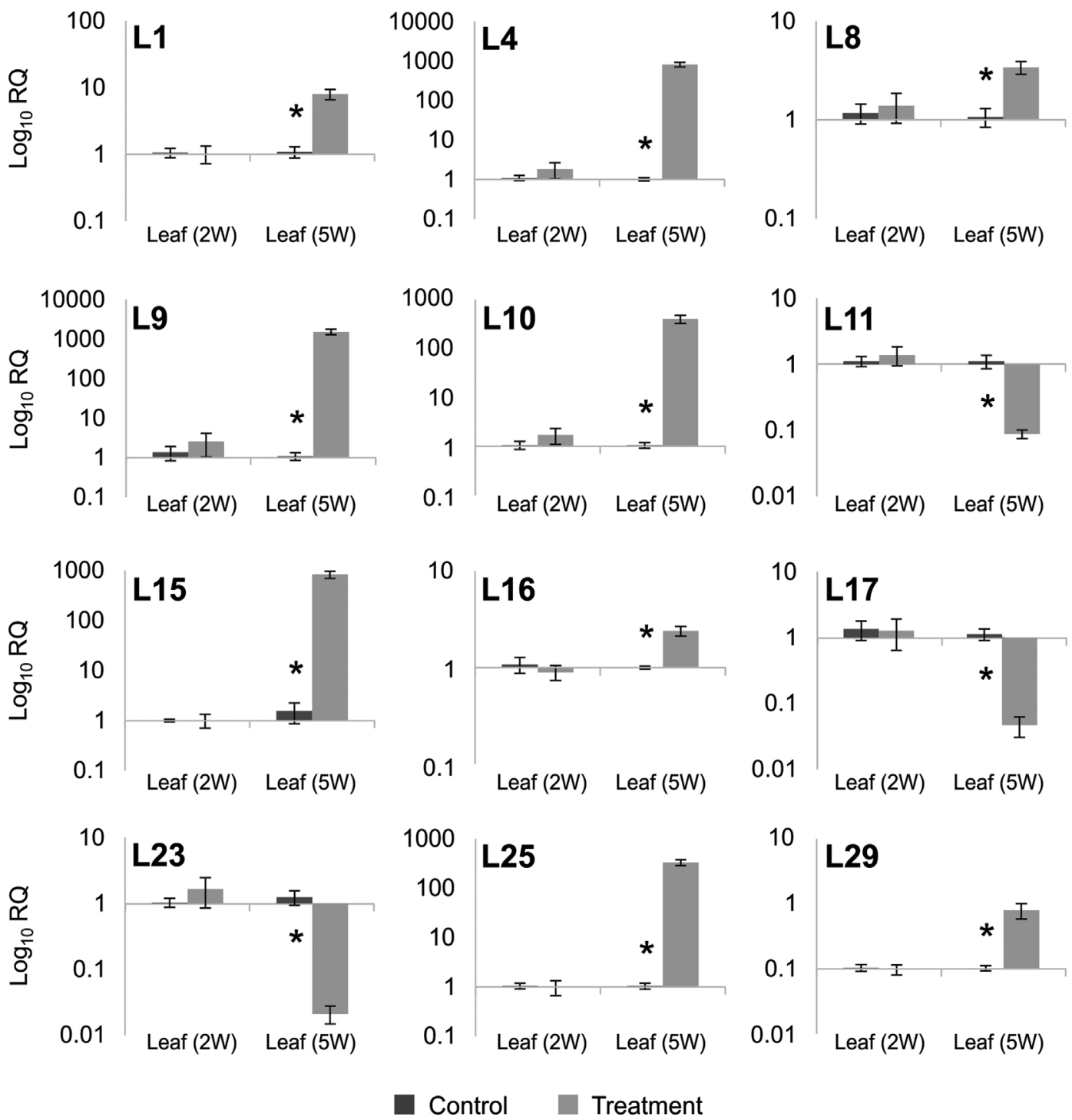

Figure 3 - RT-qPCR analysis of selected leaf transcripts. Expression is shown for the 12 transcripts that were validated by RT-qPCR. Wheat leaves were sampled from two week-old ( $2 \mathrm{~W}$ ) plants, where control plants were irrigated at $100 \%$ of field capacity (FC) and treated plants were irrigated at $75 \% \mathrm{FC}$. Five-week-old ( $5 \mathrm{~W}$ ) plants are represented by control plants irrigated at $100 \% \mathrm{FC}$, and treated plants, where irrigation was withdrawn for three weeks. The experiment was performed in triplicate biological samples, with technical triplicates for each. Relative expression was calculated by the $2^{-\Delta \Delta \mathrm{ct}}$ method. Asterisks represent significantly different (Student's $t$-test, $p \leq 0.05$ ) transcript levels. For more details on primers see Table 2 and Table S2.

leaves. In addition, the number of sequences for the fructose and mannose pathways was 3.5 times higher in leaves, while the arginine and proline metabolism pathway presented a similar number of sequences for both tissues. We also analyzed putative pathways related to the 22 upregulated sequences with annotation that were tested by RT-qPCR (Table S2). Among the 22 transcripts, 10 generated results when searched against KEGG, revealing 13 different pathways (Table 2). With the exception of L4, whose function was not linked to a specific pathway, all isotigs remained in the same enzyme classes and pathways as identified before the assembling with CAP3.

An analysis of the distribution of candidate genes across the wheat genome was done by BLAST searches against the sequenced $T$. aestivum cv. Chinese Spring ge- nome (Figure 7, Figure 8). Among the 3,987 candidate genes assembled by CAP3, 158 transcripts could not be mapped. More candidate genes were located in the $\mathrm{B}$ genome ( $p<0.001$ by the chi-square test) compared to the $\mathrm{A}$ and $\mathrm{D}$ genomes (Figure 7A). In addition, chromosomes 3B, $5 \mathrm{~B}$ and $2 \mathrm{~B}$ had more sequences related to drought response (Figure 7B). Candidate genes specific to roots or leaves and in common between the two tissues were detected in all genomes and chromosomes (Figure 7C-E). Although chromosomes $3 \mathrm{~B}, 5 \mathrm{~B}$ and $2 \mathrm{~B}$ showed the highest number of candidate genes, most of the transcripts mapping to these chromosomes were down-regulated. In fact, only chromosomes $5 \mathrm{~A}, 6 \mathrm{~B}, 7 \mathrm{~B}$ and $3 \mathrm{D}$ presented at least $10 \%$ more up-regulated transcripts than down-regulated ones. The chromosomes with more up-regulated sequences were $3 \mathrm{~B}$, 

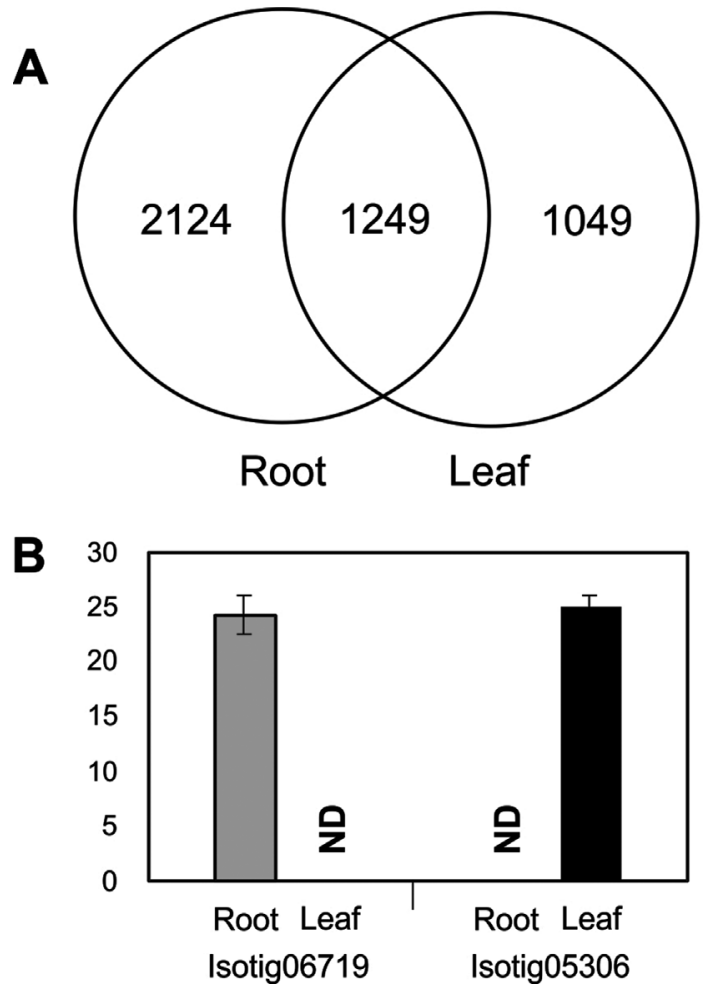

Figure 4 - Root or leaf specific candidate genes identified in response to drought stress in the wheat cultivar MGS1 Aliança. (A) Venn diagram representing the number of candidate genes obtained after DEGseq analysis. The candidate genes are distributed in root and leaf according to CAP3 assembly. (B) RT-qPCR analysis of two randomly selected specific transcripts, showing that isotig06719 (see primer sequences on Table S2) is specifically expressed in root tissue and the isotig05306 (primers CCGTGTCACTTCCCTTGATT and GGAGAGGTTGAGATGGGT GA) is expressed in leaves only. "ND" means not detected.

$5 \mathrm{~B}$ and $2 \mathrm{~A}$. The $\mathrm{CAP} 3$ assembly also allowed for the identification of no-hits candidate genes per chromosome (expression only in root or leaf and expression in both tissues), where 88 no-hit sequences were detected (Figure 8). The two chromosomes with the highest numbers of no-hit sequences were chromosomes $2 \mathrm{~B}$ and $3 \mathrm{~B}$. In these chromosomes, most of the no-hit sequences was specific to roots (Figure 8B).

\section{Transcription factors}

Transcription factors (TFs) play a central role in the plant response to drought (Tuberosa and Salvi, 2006). Thus, we searched for TFs among the differentially expressed sequences. To achieve this, the similarity of the sequences was evaluated against a plant transcription factor database (PlantTFDB) with an E-value cutoff of e-100. Several TFs, such as E2F/DP, SRS, WOX, M-type, NF-YB, GRF, LBD, CPP, GeBP, STAT, BBR-BPC, Whirly, BES1, NF-YA, NF-YC, HB-PHD, GATA, DBB, NF-X1, VOZ, CO-like, AP2, B3, SBP, Dof, ARR-B, HB-other, MIKC, EIL, Nin-like, Trihelix, G2-like, HD-ZIP, CAMTA, MYB, HSF, ERF, TALE, WRKY,
C2H2, FAR1, bHLH, NAC, bZIP, MYB related, C3H, ARF, GRAS and DREB were found (Figure S4). The species with the greatest numbers of hits were Oryza sativa japonica, Sorghum bicolor, T. aestivum and B. distachyon (data not shown).

\section{Discussion}

Rainfed wheat plants growing in the Cerrado Biome need to cope with different abiotic stresses, with drought being one of the most important factors. In this context, a wheat cultivar adapted to that region represents an excellent model to study drought response mechanisms. Here, we identified 4,422 candidate genes associated to severe drought response in both root and leaf tissues during the tillering stage of the wheat cultivar MGS1 Aliança. Although the early stages of pollen development are the most vulnerable to drought in cereals (Fischer, 1973), seed germination and early seedling growth are also considered critical stages for wheat establishment (Zhang et al., 2014). Therefore, the early phase of wheat development is an important stage to evaluate the effect of drought. Moreover, for wheat farming in the Cerrado, dry spells can occur during the tillering stage (Ribeiro Júnior et al., 2006).

The functional annotation of the transcripts reported here (Figure 1) is in agreement with other reports (Deokar et al., 2011; Li et al., 2012; Zhou et al., 2012). However, one important difference is the technique used here (454 sequencing technology) in comparison to the one used to evaluate the gene expression in previous studies. The 454 technology is an 'open' system in which gene expression can be accurately measured by counting the detected identical transcripts, potentially capturing all the transcripts in a sample (Coram et al., 2008). Although the Blast2GO analysis showed similarity of the bread wheat expressed sequences with $A$. tauschii and $H$. vulgare (Figure S3), sequences with unknown function or no-hits were also found (Figure 8B). The no-hit sequences are an important contribution of high-throughput sequencing techniques because they represent a more complete description of gene expression and should be important to understand drought stress response in wheat. In our survey, the distribution of the no-hit sequences was higher on chromosome 2B (38, considering both chromosome arms). Regarding the three wheat genome components, the B genome harbored the highest number of no-hit sequences (44) when compared to the D genome (27) and A genome (17) (Figure 8B).

The total number of identified repressed transcripts in response to drought (2,305 for roots and leaves) was higher than the number of induced transcripts $(2,117$ for both tissues). However, when considering each tissue separately, the number of repressed transcripts was lower than the induced transcripts in leaves (597 repressed and 1,017 induced) but higher in roots (1,708 repressed and 1,100 induced). A higher number of repressed transcripts under drought conditions in hexaploid wheat was also reported by 

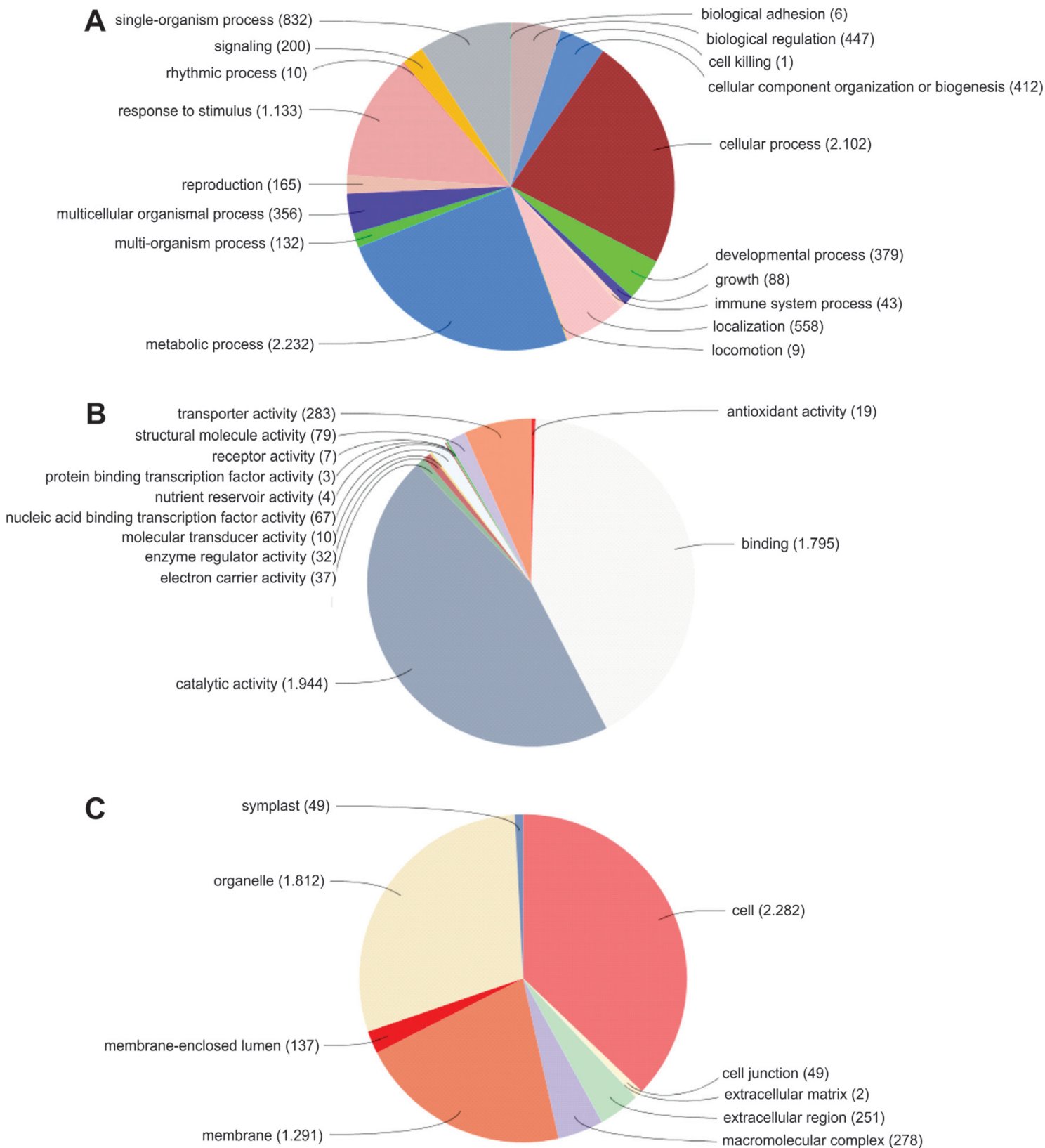

Figure 5 - Pie diagrams demonstrating the percentage of contigs and singlets generated in CAP3 within the functional categories of Gene Ontology. Results are based on Blast2GO data mining. (A) Biological process, (B) molecular function, and (C) cellular component.

other authors (Mohammadi et al., 2008; Li et al., 2012). To validate the repression/induction detected by the RNA-seq experiment, we used RT-qPCR to confirm the expression profile of 35 candidate genes ( 15 from roots and 20 from leaves). These candidate genes are representative of different pathways or code for different enzymes in the same pathway (Table S2), providing a broad validation of the RNA-seq experiment. The RT-qPCR assays revealed statistically significant differences for $73.3 \%$ and $80 \%$ sequences from root and leaf, respectively (Figure 2, Figure 3). Significant differences were not detected for the remaining sequences, but the direction of the expression profile was generally the same, and the Pearson's correlation between the RNA-seq and RT-qPCR data was 0.78 (Figure $\mathrm{S} 2)$. It is important to note that the RT-qPCR assays were done as a second and independent experiment for confirmation of the gene expression. For RNA-seq experiments reported previously by others, the RT-qPCR correlation coefficients varied from 0.58 to 0.98 (Nagalakshmi et al., 2008; Kogenaru et al., 2012). The RT-qPCR technique was also used to confirm the expression of two tissue-specific sequences found among the candidate genes (Figure 4).

An important mechanism used by plants to tolerate drought is osmotic adjustment (Nezhadahmadi et al., 
Table 2 - Biological pathways related to 10 sequences validated by RT-qPCR and the respective contigs where they assemble in CAP3.

\begin{tabular}{lccc}
\hline Primer*2 & Pathway*1 & \#Seqs & \#Enzs \\
\hline R8 & Fructose and manose metabolism & Contig607LR & ec:1.1.1.21 - reductase \\
R8 & Galactose metabolism & Contig607LR & ec:1.1.1.21 - reductase \\
R8 & Glycerolipid metabolism & Contig607LR & ec:1.1.21 - reductase \\
R8 & Glycosphingolipid biosynthesis - globoseries & Contig607LR & ec:3.2.1.22 - melibiase \\
R8 & Pentose and glucoronate interconversions & Contig607LR & ec:1.1.1.21 - reductase \\
R8 & Pyruvate metabolism & Contig607LR & ec:1.1.1.21 - reductase \\
R24 & Arginine and proline metabolism & Contig3704LR & ec:2.7.2.11 - 5-kinase; ec: 1.2.1.41 - dehydrogenase \\
R28 & Galactose metabolism & Contig575LR & ec:2.4.1.82 - galactosyltransferase, ec:3.2.1.22 - melibiase \\
R28 & Glycerolipid metabolism & Contig575LR & ec:3.2.1.22 - melibiase \\
R28 & Sphingolipid metabolism & Contig575LR & ec:3.2.1.22 - melibiase \\
L4 & Purine metabolism & Contig506LR & ec:3.6.1.3 - adenylpyrophosphatase \\
L8 & Arginine and proline metabolism & Contig5346LR & ec:1.2.1.19 - dehydrogenase \\
L8 & Beta-Alanine metabolism & Contig5346LR & ec:1.2.1.19 - dehydrogenase \\
L8 & Glycine, serine and threonine metabolism & Contig5346LR & ec:1.2.1.8 - dehydrogenase \\
L9 & Pyruvate metabolism & Contig178LR & ec:1.1.1.38 - dehydrogenase (oxaloacetate-decarboxylating) \\
L10 & Starch and sucrose metabolism & Contig472LR & ec:2.4.1.12 - synthase (UDP-forming) \\
L15 & T cell receptor signaling pathway & Contig149LR & ec:3.1.3.16 - phosphatase \\
L25 & Arginine and proline metabolism & Contig132L & ec:2.7.2.11 - 5-kinase; ec: 1.2.1.41 - dehydrogenase \\
L29 & Arginine and proline metabolism & Singlet & ec:2.7.2.11 - 5-kinase; ec: 1.2.1.41 - dehydrogenase \\
\hline
\end{tabular}

Analysis was performed with Blast2GO against the Kyoto Encyclopedia of genes and Genomes (KEGG). \#Seqs means the number of sequences in that pathway; \#Enzs indicates the number of enzymes corresponding to the sequences.

$*^{1}$ Alphabetical order based on the primer name. See more detail of the primers on Table 1 .

$*^{2}$ One primer can correspond to more than one pathway.

2013). In this process, accumulation of solutes in cells allows to decrease the osmotic potential and to maintain the cell turgor as drought stress develops. Osmoprotectants synthesized in response to drought stress include low molecular weight and highly soluble compounds, such as sugars, proline, polyols, and quaternary ammonium (PintóMarijuan and Munné-Bosch, 2013). In wheat, osmotic adjustment is positively associated with higher yield under drought stress and could partly explain the genotypic variation in stomatal response of wheat cultivars that differ in their responses to drought (Morgan and Condon, 1986; Izanloo et al., 2008). Here, we identified the sucrose metabolism as an important pathway for drought response in the cultivar MGS1 Aliança (Figure 6). When considering both tissues separately, the sucrose metabolism pathway was still found to be among the three most important ones. There are four enzymes that play a key role in starch metabolism: EC 2.4.1.13 - Susase, EC 2.7.7.27 - AGPase, EC 2.4.1.21 - STSase and EC, 2.4.1.18 - SBE (Yang et al., 2004), and all these enzymes, except for AGPase, were activated during the water stress evaluated in this study. These enzymes also played an important role when previously evaluated in wheat plants grown under water stress conditions (Ahmadi and Baker, 2001). In addition, starch and sucrose metabolism, phenylpropanoid biosynthesis, and glyoxylate and dicarboxylate metabolism were also the most frequently detected KEGG pathways in a transcriptome analysis of Paulownia australis grown under drought conditions (Dong et al., 2014). Furthermore, proline is a solute that plays a role as a protective agent for cells under osmotic stress, performing an important function in the drought stress response (Nezhadahmadi et al., 2013). In our study, the P5CS1 and DELTA-OAT transcripts, related to proline biosynthesis, were up-regulated in leaf and root tissues (Table S4). In contrast, the ALDH12A1 and P5CS2 transcripts were up-regulated only in leaves, and the ALDH1 transcript was up-regulated in roots only. In fact, the arginine and proline metabolism pathway is among the top 20 pathways found to be induced in leaves (Figure 6).

Other transcripts already linked to the drought response were found among the candidate genes (Table S4). These transcripts include glutathione S-transferase and others related to glutathione biosynthesis and catabolism (GGT1, GSTU25, AT1G65820 and GSTU18 down-regulated in roots; GSH1 and OXP1 up-regulated in roots; GR1 up-regulated in leaves; GSTL3 up-regulated in leaves and roots, and ERD9 down-regulated in roots and up-regulated in leaves); dehydrins (DHN1 up-regulated in leaves and roots); and other late embryogenesis abundant (LEA) proteins (LEA7 was down- and up-regulated in leaves, while up-regulation was observed for AtLEA4-1, LEA14, LEA, 


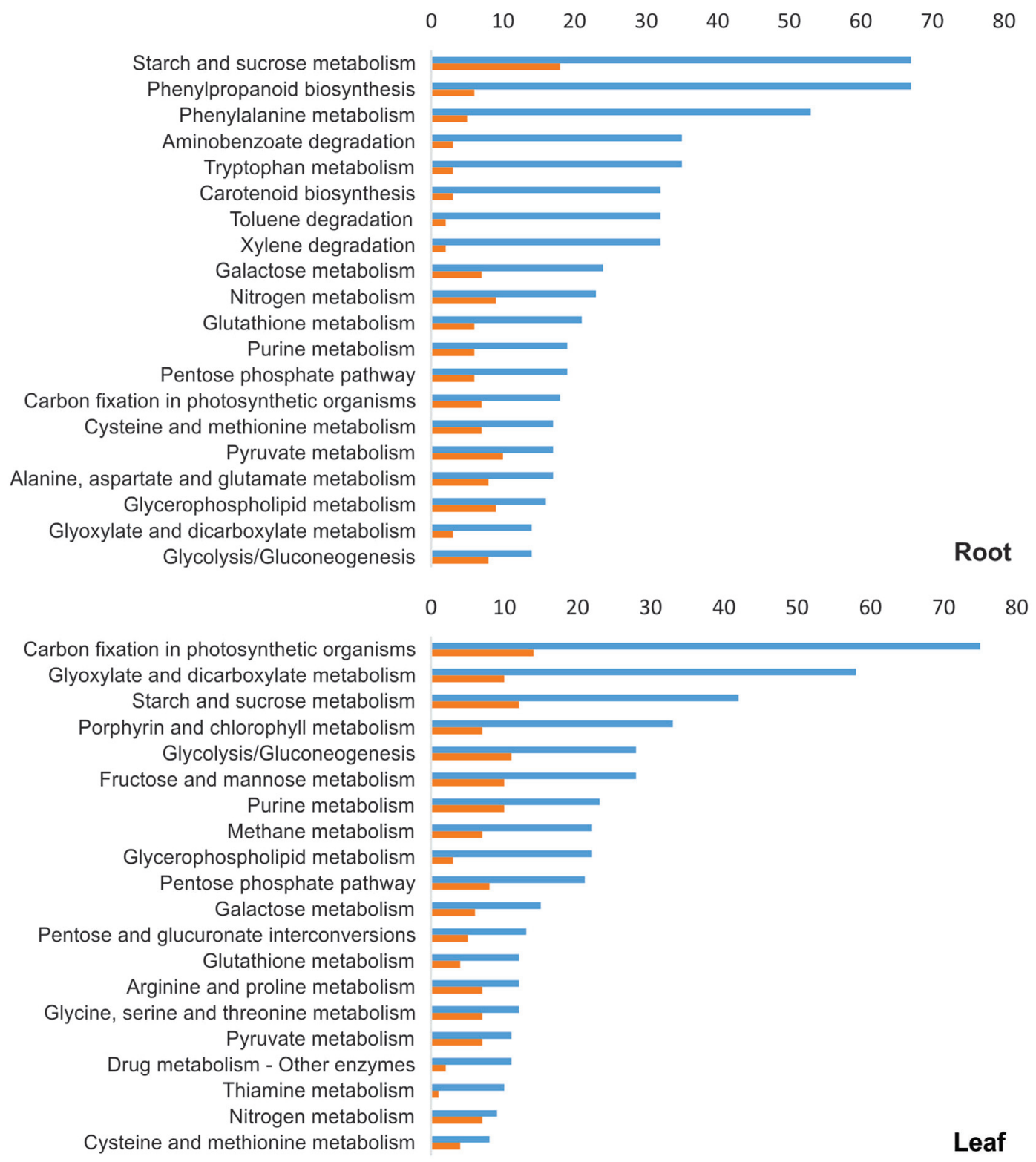

Figure 6 - Top 20 biological pathways of root and leaf tissues activated in the wheat cultivar MGS1 Aliança under drought conditions. Sequences were analyzed by Blast2GO against the Kyoto Encyclopedia of Genes and Genomes (KEGG). Blue bars represent the number of sequences and orange bars represent the number of enzymes.

LEA4-5 and dehydrin DHN1; in roots, LEA14, AT2G46140, AtLEA4-1 and LEA7 were up-regulated, while ACC1 was down-regulated). These proteins are important enzymes involved in stress responses, helping to cope with detoxification and reducing cellular damage by recovering denatured proteins and stabilizing membranes (Koag et al., 2003; Umezawa et al., 2006). For example, the wheat LEA genes PMA1959 and PMA80, improved water deficit resistance in rice (Cheng et al., 2002), and the wheat dehydrin, DHN-5, improved drought tolerance when overexpressed in Arabidopsis thaliana (Brini et al., 2007). Moreover, these proteins are among the differentially expressed transcripts detected in hard red winter wheat cultivars submitted to water-deficit conditions (Reddy et al., 2014).

Another strategy to decrease the effects of drought is to retard leaf senescence (a process that is accelerated in drought-sensitive genotypes). In practical terms, leaf senescence leads to reduced yield, meaning that the suppression of drought-induced leaf senescence is desirable (Jewell et al., 2010). In the MGS1 Aliança genotype analyzed here, candidate genes with GO terms related to leaf senescence were found in both tissues (RCA, HAI1 and LTI65 in leaf and SAG12, SAG29, LTI65, ARF1, WRYK70 and OPR1 in root) (Table S4). Moreover, many candidate genes related to the biosynthesis of the hormone abscisic acid 

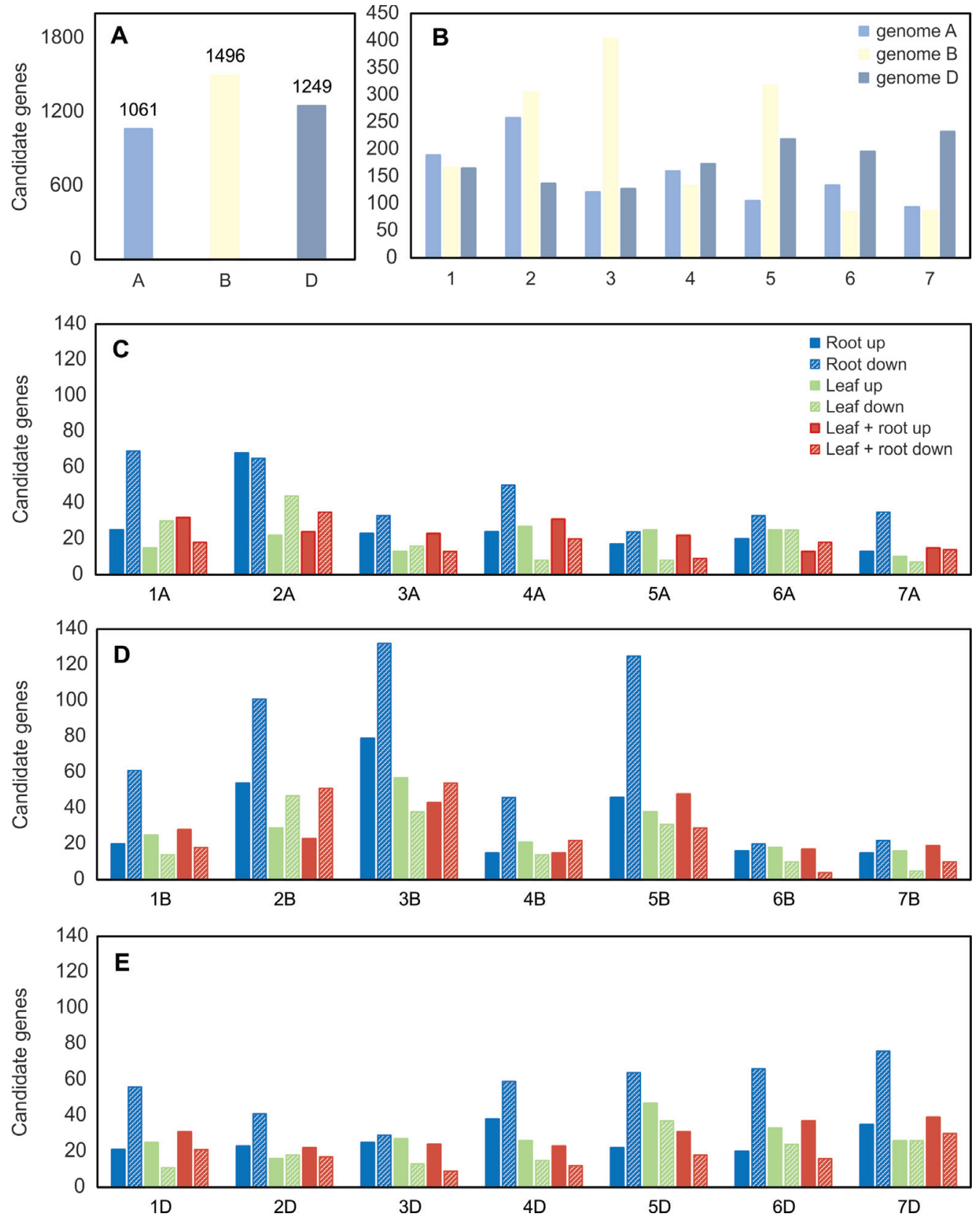

Figure 7 - Genome distribution of the candidate genes associated to drought response in the wheat cultivar MGS1 Aliança. Sequences were retrieved by BLAST against the Triticum aestivum cv. Chinese Spring genome at an E-value cutoff 1e-100. (A) Number of candidate genes per genome. (B) Total number of candidate genes per chromosome. (C), (D) and (E) Number of candidate genes that are up- or down-regulated and that are specific to roots, leaves, in common between both tissues for genome A, B and D, respectively.

(ABA) were also found in our study; for example, the AAO3 and NCED3 (9-cis-epoxycarotenoid dioxygenase) transcripts, which code for important enzymes in the ABA biosynthesis pathway (Table S4). Overexpression of the NCED3 transcript in Arabidopsis leads to tolerance of drought (Iuchi et al., 2001). ABA synthesis increases in plants under water stress, inducing stomatal closure, reducing water loss via transpiration, and shaping transcript expression, which is also important for response to salinity and cold (Shinozaki and Yamaguchi-Shinozaki, 1997;
Mahajan and Tuteja, 2005; Guóth et al., 2009). In addition, transcripts related to ABA transduction signaling were also identified; for example, the OST1 transcript, which responds to $\mathrm{ABA}$ stimulus controlling stomatal closure (Mustilli et al., 2002; Yoshida et al., 2002).

The candidate genes induced by drought stress and classified as "transcription factors" were less numerous than reported by Li et al. (2012). In this category, TFs such as bZIP, CBF, EREBP, WRKY, MADS, NAC and Myb were found (Figure S4). Some of these TFs have been ana- 
A

\begin{tabular}{|c|c|c|c|}
\cline { 2 - 4 } \multicolumn{1}{c|}{} & A & B & D \\
\hline 1 & 189 & 166 & 165 \\
\hline 2 & 258 & 305 & 137 \\
\hline 3 & 121 & 403 & 127 \\
\hline 4 & 160 & 133 & 173 \\
\hline 5 & 105 & 317 & 219 \\
\hline 6 & 134 & 85 & 196 \\
\hline 7 & 94 & 87 & 232 \\
\hline \multicolumn{4}{|c}{ Total } \\
B
\end{tabular}

\begin{tabular}{|c|c|c|c|}
\cline { 2 - 4 } \multicolumn{1}{c|}{} & A & B & D \\
\hline 1 & 94 & 81 & 77 \\
\hline 2 & 133 & 155 & 64 \\
\hline 3 & 56 & 211 & 54 \\
\hline 4 & 74 & 61 & 97 \\
\hline 5 & 41 & 171 & 86 \\
\hline 6 & 53 & 36 & 86 \\
\hline 7 & 48 & 37 & 111 \\
\hline \multicolumn{4}{|c}{ Root }
\end{tabular}

\begin{tabular}{|c|c|c|c|}
\cline { 2 - 4 } \multicolumn{1}{c|}{} & A & B & D \\
\hline 1 & 45 & 39 & 36 \\
\hline 2 & 66 & 76 & 34 \\
\hline 3 & 29 & 95 & 40 \\
\hline 4 & 35 & 35 & 41 \\
\hline 5 & 33 & 69 & 84 \\
\hline 6 & 50 & 28 & 57 \\
\hline 7 & 17 & 21 & 52 \\
\hline \multicolumn{4}{|c|}{ Leaf } \\
\hline
\end{tabular}

\begin{tabular}{|c|c|c|c|}
\cline { 2 - 4 } \multicolumn{1}{c|}{} & A & B & D \\
\hline 1 & 50 & 46 & 52 \\
\hline 2 & 59 & 74 & 39 \\
\hline 3 & 36 & 97 & 33 \\
\hline 4 & 51 & 37 & 35 \\
\hline 5 & 31 & 77 & 49 \\
\hline 6 & 31 & 21 & 53 \\
\hline 7 & 29 & 29 & 69 \\
\hline \multicolumn{4}{|c|}{ Root + Leaf }
\end{tabular}

\begin{tabular}{|c|c|c|c|}
\cline { 2 - 4 } \multicolumn{1}{c|}{} & A & B & D \\
\hline 1 & 3 & 7 & 5 \\
\hline 2 & 1 & 15 & 8 \\
\hline 3 & 3 & 12 & 1 \\
\hline 4 & 3 & 3 & 1 \\
\hline 5 & 2 & 5 & 3 \\
\hline 6 & 3 & 2 & 8 \\
\hline 7 & 2 & 0 & 1 \\
\hline \multicolumn{3}{|c}{} \\
\hline
\end{tabular}

\begin{tabular}{|c|c|c|c|}
\cline { 2 - 4 } \multicolumn{1}{c|}{} & A & B & D \\
\hline 1 & 1 & 5 & 4 \\
\hline 2 & 1 & 11 & 6 \\
\hline 3 & 2 & 7 & 1 \\
\hline 4 & 2 & 3 & 1 \\
\hline 5 & 1 & 2 & 1 \\
\hline 6 & 3 & 1 & 3 \\
\hline 7 & 2 & 0 & 1 \\
\hline
\end{tabular}

\begin{tabular}{|c|c|c|c|}
\cline { 2 - 4 } \multicolumn{1}{c|}{} & A & B & D \\
\hline 1 & 1 & 1 & 0 \\
\hline 2 & 0 & 2 & 1 \\
\hline 3 & 0 & 0 & 0 \\
\hline 4 & 0 & 0 & 0 \\
\hline 5 & 0 & 0 & 1 \\
\hline 6 & 0 & 1 & 2 \\
\hline 7 & 0 & 0 & 0 \\
\hline \multicolumn{4}{|c|}{ Leaf } \\
\hline
\end{tabular}

\begin{tabular}{|c|c|c|c|}
\cline { 2 - 4 } \multicolumn{1}{c|}{} & A & B & D \\
\hline 1 & 1 & 1 & 1 \\
\hline 2 & 0 & 2 & 1 \\
\hline 3 & 1 & 5 & 0 \\
\hline 4 & 1 & 0 & 0 \\
\hline 5 & 1 & 3 & 1 \\
\hline 6 & 0 & 0 & 3 \\
\hline 7 & 0 & 0 & 0 \\
\hline \multicolumn{4}{|c|}{ Root + Leaf }
\end{tabular}

Figure 8 - Heat map showing the localization of the candidate genes associated to drought response in the wheat cultivar MGS1 Aliança. Hit distribution by tissue was obtained by BLAST against the genome of Triticum aestivum cv. Chinese spring at an E-value cutoff 1e-100. Numbers represent the hit distribution for each chromosome. "Total" means hit distribution of all sequences. "Root" means hit distribution of transcripts specifically expressed in roots. "Leaf" means hit distribution of transcripts specifically expressed in leaf. "Root + Leaf" means hit distribution of transcripts expressed in common between root and leaf. Darker colors mean higher number of reads. (A) All the candidate genes. (B) Only the candidate genes classified as no-hit.

lyzed by others, being up-regulated in roots of a droughttolerant genotype (Okay et al., 2014) and induced by drought stress in different species of Triticum (Baloglu et al., 2014). A large number of TFs has also been found to be differentially regulated in response to heat, drought and their combination (Liu et al., 2015). In addition, an increase in drought tolerance has been demonstrated in transgenic plants over-expressing some of those TFs, such as transgenic Arabidopsis expressing NAC TF or TaMYB2A (Mao et al., 2011; Li et al., 2014), rice expressing the DREB1A from Arabidopsis (Ravikumar et al., 2014), wheat plants overexpressing MYB-TF (TaPIMP1) or TaERF3 (Zhang et al., 2012; Rong et al., 2014) and tobacco expressing TaABP1 (bZIP-TF) or TaWRKY10 (Cao et al., 2012; Wang et al., 2013).

One of the practical applications of the isolation of drought-related genes is the development of transgenic plants that are more tolerant to drought stress. So far, several papers have reported on that approach, using transcripts belonging to some of the functional groups discussed above. Examples in transgenic wheat include osmoprotectant genes (Abebe et al., 2003; Vendruscolo et al., 2007), LEA proteins (Sivamani et al., 2000; Bahieldin et al., 2005), a gene from the $\mathrm{C}_{4}$ pathway (Qin et al., 2015) and TFs (Morran et al., 2011; Xue et al., 2011; Saint Pierre et al., 2012; Zhang et al., 2012). In these reports, the experi- ments were performed with genes obtained from $A$. thaliana (DREB), Atriplex hortensis (BADH), Escherichia coli ( $m t l D$ or betA), barley (HVA1), cotton (GhDREB), rice (SNAC1), or Vigna aconitifolia (P5CS). Only a few studies have been performed with genes isolated from wheat, such as TaDREB2, TaDREB3, TaNAC69-1, or TaPIMP1 (Morran et al., 2011; Xue et al., 2011; Zhang et al., 2012). So far, field data regarding the performance of these transgenic plants have not been conclusive, with the transgenic lines not outperforming the controls or showing unstable performance along the years (Bahieldin et al., 2005; Saint Pierre et al., 2012). Nonetheless, it should be interesting to evaluate the production of these plants in the Cerrado region.

The candidate genes found here are distributed across all component genomes and chromosomes of the wheat genome (Figure 7, Figure 8). The number of sequences belonging to the $\mathrm{B}$ genome was higher in comparison with the $\mathrm{A}$ and $\mathrm{D}$ genomes. During evolution, the diploid genomes A and B (T. urartu and an unknown species of section Sitopsis, respectively) underwent an alloploydization event to form the tetraploid wheat $T$. turgidum, followed by another alloploydization with the $\mathrm{D}$ genome (T. turgidum) (Leach et al., 2014). It has been shown that there is a tendency of $\mathrm{B}$ genome homoeoloci to contribute more to gene expression in wheat than A or D genome homoeoloci 
(Leach et al., 2014). Moreover, the wild T. turgidum (AABB genome), which is the ancestor of cultivated $T$. turgidum and T. aestivum (Budak et al., 2013), contains a gene pool enriched for various agronomic traits, including drought tolerance (Peleg et al., 2008; Ergen et al., 2009). That information could encourage investigations on drought response in tetraploid wheat, and that tolerance could be incorporated into synthetic lines. However, it is important to note that the interaction among the $\mathrm{A}, \mathrm{B}$ and $\mathrm{D}$ genomes could activate or silence homeologous genes (Wang et al., 2011), making the introduction of genes from the $\mathrm{B}$ genome into the hexaploid genome a laborious task. Figures 7 and 8 also show that chromosomes 3B, 5B and 2B contribute with a greater number of drought-related transcripts in both roots and leaves. In wheat, quantitative trait loci (QTL) identified under different water regimes have been reported for traits like, for example, canopy temperature, carbon isotope discrimination, photosynthetic parameters and yield or yield components (Sheoran et al., 2016). Virtually all wheat chromosomes and component genomes contain QTL for drought tolerance, most of them explaining a small fraction of the observed phenotypic variation. When focusing on chromosomes 3B, 5B and 2B, the major regions identified in our study, QTL for a number of traits correlated to drought tolerance have been described like, for instance, abscisic acid, canopy temperature, carbon isotope discrimination, chlorophyll content, coleoptile length, flag leaf rolling index, flag leaf senescence, grain number, grain size, grain weight, normalized difference vegetation index, water soluble carbohydrates, phenology (anthesis, heading, maturity), plant height, and yield (Sheoran et al., 2016). The co-localization of the QTL with some of the candidate genes obtained in this survey could be an interesting target for future work.

In conclusion, the present study allowed for the identification of genes related to important pathways for drought response in the wheat cultivar MGS1 Aliança, a well-adapted cultivar for rainfed farming in the Cerrado Biome. Clearly, our results showed that the main pathways activated under water deprivation differ for roots and leaves. Increments in drought tolerance through conventional and biotechnological approaches should take this difference into consideration. The drought stress-related transcripts described here will be further characterized to provide targets of interest for breeders. They are also important to elucidate the complex regulatory network(s) of the drought response. The characterization of candidate genes that are differentially expressed among droughttolerant and -sensitive genotypes can help identify useful molecular markers and candidate genes. In the long run, the interesting targets and molecular markers can be used to achieve more sustainable wheat production.

\section{Acknowledgments}

We thank the Coordenação de Aperfeiçoamento de Pessoal de Nível Superior (CAPES) for a PhD scholarship granted to LBPB. The study received financial support from Embrapa (Projects "Fenotipagem, avaliação de mecanismos de tolerância e associação genômica aplicadas ao desenvolvimento de recursos genéticos de cereais adaptados à seca" and "Desenvolvimento de recursos genéticos de cereais tolerantes à seca"). We also thank Dr. Márcio Só e Silva (Embrapa Trigo) for providing the MGS1 Aliança seeds, Dr. Edson Costenaro (Embrapa Trigo) for helping with the water potential measurements and Dr Cláudio Brondani (Embrapa Arroz e Feijão) for the RNA quality analysis using Bioanalyzer.

\section{References}

Abebe T, Guenzi AC, Martin B and Cushman JC (2003) Tolerance of mannitol-accumulating transgenic wheat to water stress and salinity. Plant Physiol 131:1748-1755.

Ahmadi A and Baker DA (2001) The effect of water stress on the activities of key regulatory enzymes of the sucrose to starch pathway in wheat. Plant Growth Regul 35:81-91.

Asseng S, Ewert F, Martre P, Rötter RP, Lobell DB, Cammarano D, Kimball BA, Ottman MJ, Wall GW, White JW, et al. (2015) Rising temperatures reduce global wheat production. Nat Clim Change 5:143-147.

Bahieldin A, Mahfouz HT, Eissa HF, Saleh OM, Ramadan AM, Ahmed IA, Dyer WE, El-Itriby HA and Madkour MA (2005) Field evaluation of transgenic wheat plants stably expressing the $H V A 1$ gene for drought tolerance. Physiol Plant 123:421-427.

Baloglu MC, Inal B, Kavas M and Unver T (2014) Diverse expression pattern of wheat transcription factors against abiotic stresses in wheat species. Gene 550:117-122.

Bär R, Rouholahnedjad E, Rahman K, Abbaspour KC and Lehmann A (2015) Climate change and agricultural water resources: A vulnerability assessment of the Black Sea catchment. Environ Sci Policy 46:57-69.

Barrs HD and Weatherley PE (1962) A re-examination of the relative turgidity technique for estimating water deficits in leaves. Aust J Biol Sci 15:413-428.

Brini F, Hanin M, Lumbreras V, Amara I, Khoudi H, Hassairi A, Pagès M and Masmoudi K (2007) Overexpression of wheat dehydrin DHN-5 enhances tolerance to salt and osmotic stress in Arabidopsis thaliana. Plant Cell Rep 26:20172026.

Budak H, Hussain B, Khan Z, Ozturk NZ and Ullah N (2015) From genetics to functional genomics: Improvement in drought signaling and tolerance in wheat. Front Plant Sci 6:102.

Budak H, Kantar M and Yucebilgili Kurtoglu K (2013) Drought tolerance in modern and wild wheat. Sci World J ID 548246.

Cao XY, Chen M, Xu ZS, Chen YF, Li LC, Yu YH, Liu YN and MA YZ (2012) Isolation and functional analysis of the bZIP transcription factor gene $T a A B P 1$ from a chinese wheat landrace. J Integr Agr 11:1580-1591.

Cheng Z, Targolli J, Huang X and Wu R (2002) Wheat LEA genes, PMA80 and PMA1959, enhance dehydration toler- 
ance of transgenic rice (Oryza sativa L.). Mol Breeding 10:71-82.

Comissão Brasileira de Pesquisa de Trigo e Triticale (2016) Informações Técnicas para Trigo e Triticale - Safra 2016. In: $9^{a}$ Reunião da Comissão Brasileira de Pesquisa de Trigo e Triticale. Passo Fundo, 228 p.

Coram TE, Brown-Guedira G and Chen X (2008) Using transcriptomics to understand the wheat genome. CAB Persp Agric, Vet Sci, Nutr Nat Resour 3:1-9.

De Mori C and Só e Silva M (2013) Panorama da triticultura no Brasil e em Minas Gerais. Inf Agropec 34:7-18.

Deokar AA, Kondawar V, Jain PK, Karuppayil SM, Raju NL, Vadez V, Varshney RK and Srinivasan R (2011) Comparative analysis of expressed sequence tags (ESTs) between drought-tolerant and -susceptible genotypes of chickpea under terminal drought stress. BMC Plant Biol 11:70.

Dong Y, Fan G, Zhao Z and Deng M (2014) Transcriptome expression profiling in response to drought stress in Paulownia australis. Int J Mol Sci 15:4583-4607.

Edgar R, Domrachev M and Lash AE (2002) Gene Expression Omnibus: NCBI gene expression and hybridization array data repository. Nucleic Acids Res 30:207-210.

Ergen NZ, Thimmapuram J, Bohnert HJ and Budak H (2009) Transcriptome pathways unique to dehydration tolerant relatives of modern wheat. Funct Integr Genomic 9:377-396.

Fischer RA (1973) The effect of water stress at various stages of development on yield processes in wheat. In: Slatyer RO (ed) Plant Response to Climate Factors. UNESCO, Paris, pp 233-241.

Fischer RA, Rees D, Sayre KD, Lu ZM, Condon AG and Saavedra AL (1998) Wheat yield progress associated with higher stomatal conductance and photosynthetic rate, and cooler canopies. Crop Sci 38:1467-1475.

Foulkes MJ, Sylvester-Bradley R, Weightman R and Snape JW (2007) Identifying physiological traits associated with improved drought resistance in winter wheat. Field Crop Res 103:11-24.

Götz S, García-Gómez JM, Terol J, Williams TD, Nagaraj SH, Nueda MJ, Robles M, Talón M, Dopazo J and Conesa A (2008) High-throughput functional annotation and data mining with the Blast2GO suite. Nucleic Acids Res 36:34203435 .

Guóth A, Tari I, Gallé Á, Csiszár J, Pécsváradi A, Cseuz L and Erdei L (2009) Comparison of the drought stress responses of tolerant and sensitive wheat cultivars during grain filling: Changes in flag leaf photosynthetic activity, ABA levels, and grain yield. J Plant Growth Regul 28:167-176.

Hsiao TC (1973) Plant responses to water stress. Ann Rev Plant Physiol 24:519-570.

Huang X and Madan A (1999) CAP3: A DNA sequence assembly program. Genome Res 9:868-877.

Iuchi S, Kobayashi M, Taji T, Naramoto M, Seki M, Kato T, Tabata S, Kakubari Y, Yamaguchi-Shinozaki K and Shinozaki K (2001) Regulation of drought tolerance by gene manipulation of 9-cis-epoxycarotenoid dioxygenase, a key enzyme in abscisic acid biosynthesis in Arabidopsis. Plant J 27:325-333.

Izanloo A, Condon AG, Langridge P, Tester $\mathrm{M}$ and Schnurbusch $\mathrm{T}$ (2008) Different mechanisms of adaptation to cyclic water stress in two South Australian bread wheat cultivars. J Exp Bot 59:3327-3346.
IWGSC - International Wheat Genome Sequencing Consortium (2014) A chromosome-based draft sequence of the hexaploid bread wheat (Triticum aestivum) genome. Science 345:1251788.

Jewell MC, Campbell BC and Godwin ID (2010) Transgenic plants for abiotic stress resistance. In: Kole C, Michler $\mathrm{CH}$, Abbott AG and Hall TC (eds) Transgenic Crop Plants. Volume 2: Utilization and Biosafety. Springer, Berlin, pp 67-132.

Jin J, Zhang H, Kong L, Gao G and Luo J (2014) PlantTFDB 3.0: A portal for the functional and evolutionary study of plant transcription factors. Nucleic Acids Res 42:D1182-D1187.

Koag MC, Fenton RD, Wilkens S and Close TJ (2003) The binding of maize DHN1 to lipid vesicles. Gain of structure and lipid specificity. Plant Physiol 131:309-316.

Kogenaru S, Yan Q, Guo Y and Wang N (2012) RNA-seq and microarray complement each other in transcriptome profiling. BMC Genomics 13:629.

Leach LJ, Belfield EJ, Jiang C, Brown C, Mithani A and Harberd NP (2014) Patterns of homoeologous gene expression shown by RNA sequencing in hexaploid bread wheat. BMC Genomics 15:276.

Li H and Durbin R (2010) Fast and accurate long-read alignment with Burrows-Wheeler transform. Bioinformatics 26:589595.

Li H, Handsaker B, Wysoker A, Fennell T, Ruan J, Homer N, Marth G, Abecasis G, Durbin R and 1000 Genome Project Data Processing Subgroup (2009) The Sequence Alignment/Map (SAM) Format and SAMtools. Bioinformatics 25:2078-2079.

Li X, Yang X, Hu Y, Yu X and Li Q (2014) A novel NAC transcription factor from Suaeda liaotungensis K. enhanced transgenic Arabidopsis drought, salt, and cold stress tolerance. Plant Cell Rep 33:767-778.

Li YC, Meng FR, Zhang CY, Zhang N, Sun MS, Ren JP, Niu HB, Wang X and Yin J (2012) Comparative analysis of water stress-responsive transcriptomes in drought-susceptible and -tolerant wheat (Triticum aestivum L.). J Plant Biol 5:349360.

Liu Z, Xin M, Qin J, Peng H, Ni Z, Yao Y and Sun Q (2015) Temporal transcriptome profiling reveals expression partitioning of homeologous genes contributing to heat and drought acclimation in wheat (Triticum aestivum L.). BMC Plant Biol 15:152.

Long XY, Wang JR, Ouellet T, Rocheleau H, Wei YM, Pu ZE, Jiang QT, Lan XJ and Zheng YL (2010) Genome-wide identification and evaluation of novel internal control genes for Q-PCR based transcript normalization in wheat. Plant Mol Biol 74:307-311.

Mahajan S and Tuteja N (2005) Cold, salinity and drought stresses: An overview. Arch Biochem Biophys 444:139-158.

Mao X, Jia D, Li A, Zhang H, Tian S, Zhang X, Jia J and Jing R (2011) Transgenic expression of TaMYB2A confers enhanced tolerance to multiple abiotic stresses in Arabidopsis. Funct Integr Genomic 11:445-465.

Mohammadi M, Kav NN and Deyholos MK (2008) Transcript expression profile of water-limited roots of hexaploid wheat (Triticum aestivum 'Opata'). Genome 51:357-367.

Morgan JM and Condon AG (1986) Water use, grain yield, and osmoregulation in wheat. Funct Plant Biol 13:523-532. 
Morran S, Eini O, Pyvovarenko T, Parent B, Singh R, Ismagul A, Eliby S, Shirley N, Langridge P and Lopato S (2011) Improvement of stress tolerance of wheat and barley by modulation of expression of DREB/CBF factors. Plant Biotech $\mathrm{J}$ 9:230-249.

Mustilli AC, Merlot S, Vavasseur A, Fenzi F and Giraudat J (2002) Arabidopsis OST1 protein kinase mediates the regulation of stomatal aperture by abscisic acid and acts upstream of reactive oxygen species production. Plant Cell 14:3089-3099.

Nagalakshmi U, Wang Z, Waern K, Shou C, Raha D, Gerstein M and Snyder M (2008) The transcriptional landscape of the yeast genome defined by RNA sequencing. Science 320:1344-1349.

Nezhadahmadi A, Prodhan ZH and Faruq G (2013) Drought tolerance in wheat. Sci World J ID 610721.

Okay S, Derelli E and Unver T (2014) Transcriptome-wide identification of bread wheat WRKY transcription factors in response to drought stress. Mol Genet Genomics 289:765-781.

Paolacci AR, Tanzarella OA, Porceddu E and Ciaffi M (2009) Identification and validation of reference genes for quantitative RT-PCR normalization in wheat. BMC Mol Biol 10:11.

Peleg ZVI, Saranga Y, Krugman T, Abbo S, Nevo E and Fahima T (2008) Allelic diversity associated with aridity gradient in wild emmer wheat populations. Plant Cell Environ 31:3949.

Pintó-Marijuan M and Munné-Bosch S (2013) Ecophysiology of invasive plants: Osmotic adjustment and antioxidants. Trends Plant Sci 18:660-666.

Qin N, Xu W, Hu L, Li Y, Wang H, Qi X, Fang Y and Hua X (2015) Drought tolerance and proteomics studies of transgenic wheat containing the maize $\mathrm{C}_{4}$ phosphoenolpyruvate carboxylase $(P E P C)$ gene. Protoplasma DOI 10.1007/s00709-015-0906-2.

Ravikumar G, Manimaran P, Voleti SR, Subrahmanyam D, Sundaram RM, Bansal KC, Viraktamath BC and Balachandran SM (2014) Stress-inducible expression of AtDREB1A transcription factor greatly improves drought stress tolerance in transgenic indica rice. Transgenic Res 23:421-439.

Reddy SK, Liu S, Rudd JC, Xue Q, Payton P, Finlayson SA, Mahan J, Akhunova A, Holalu SV and Lu N (2014) Physiology and transcriptomics of water-deficit stress responses in wheat cultivars TAM 111 and TAM 112. J Plant Physiol 171:1289-1298.

Reynolds M, Dreccer F and Trethowan R (2007) Drought-adaptive traits derived from wheat wild relatives and landraces. J Exp Bot 58:177-186.

Ribeiro Junior WQ, Ramos MLG, Vasconcelos U, Trindade MG, Ferreira FM, Siqueira MMH, Silva HLM, Rodrigues GC, Guerra AF, Rocha OC, et al. (2006) Fenotipagem para Tolerância à Seca Visando o Melhoramento Genético do Trigo no Cerrado. Circular Técnica Online 27. Embrapa Trigo, Passo Fundo, 17 p.

Rong W, Qi L, Wang A, Ye X, Du L, Liang H, Xin Z and Zhang Z (2014) The ERF transcription factor TaERF3 promotes tolerance to salt and drought stresses in wheat. Plant Biotechnol J 12:468-479.

Saint Pierre C, Crossa JL, Bonnett D, Yamaguchi-Shinozaki K and Reynolds MP (2012) Phenotyping transgenic wheat for drought resistance. J Exp Bot 63:1799-1808.
Scheeren PL, Caierão E, Silva MS, Nascimento AJ, Caetano VR, Bassoi MC, Brunetta D, Albrecht JC, Quadros WJ, Sousa PG, et al. (2008) Challenges to wheat production in Brazil. In: Reynolds MP, Pietragalla J and Braun HJ (eds) International Symposium on Wheat Yield Potential: Challenges to International Wheat Breeding. CIMMYT, Mexico City, DF, pp 167-170.

Schmittgen TD and Livak KJ (2008) Analyzing real-time PCR data by the comparative $C_{\mathrm{T}}$ method. Nat Protoc 3:11011108.

Sheoran S, Malik R, Narwal S, Tyagi BS, Mittal V, Kharub AS, Tiwari V and Sharma I (2016) Genetic and molecular dissection of drought tolerance in wheat and barley. J Wheat Res 7:1-13.

Shinozaki K and Yamaguchi-Shinozaki K (1997) Gene expression and signal transduction in water-stress response. Plant Physiol 115:327-334.

Siqueira OJW, Steinmetz S, Ferreira MF, Costa AC and Wozniak MA (2000) Mudanças climáticas projetadas através dos modelos GISS e reflexos na produção agrícola brasileira. Rev Bras Agrometeorol 8:311-320.

Sivamani E, Bahieldin A, Wraith JM, Al-Niemi T, Dyer WE, Ho THD and Qu R (2000) Improved biomass productivity and water use efficiency under water deficit conditions in transgenic wheat constitutively expressing the barley $H V A 1$ gene. Plant Sci 155:1-9.

Streck NA and Alberto CM (2006) Estudo numérico do impacto da mudança climática sobre o rendimento de trigo, soja e milho. Pesq Agropec Bras 41:1351-1359.

Tuberosa R and Salvi S (2006) Genomics-based approaches to improve drought tolerance of crops. Trends Plant Sci 11:405-412.

Umezawa T, Fujita M, Fujita Y, Yamaguchi-Shinozaki K and Shinozaki K (2006) Engineering drought tolerance in plants: Discovering and tailoring genes to unlock the future. Curr Opin Biotechnol 17:113-122.

Vendruscolo ECG, Schuster I, Pileggi M, Scapim CA, Molinari HBC, Marur CJ and Vieira LGE (2007) Stress-induced synthesis of proline confers tolerance to water deficit in transgenic wheat. J Plant Physiol 164:1367-1376.

Xue GP, McIntyre CL, Chapman S, Bower NI, Way H, Reverter A, Clarke B and Shorter R (2006) Differential gene expression of wheat progeny with contrasting levels of transpiration efficiency. Plant Mol Biol 61:863-881.

Xue GP, McIntyre CL, Glassop D and Shorter R (2008) Use of expression analysis to dissect alterations in carbohydrate metabolism in wheat leaves during drought stress. Plant Mol Biol 67:197-214.

Xue GP, Way HM, Richardson T, Drenth J, Joyce PA and McIntyre CL (2011) Overexpression of TaNAC69 leads to enhanced transcript levels of stress up-regulated genes and dehydration tolerance in bread wheat. Mol Plant 4:697-712.

Yang J, Zhang J, Wang Z, Xu G and Zhu Q (2004) Activities of key enzymes in sucrose-to-starch conversion in wheat grains subjected to water deficit during grain filling. Plant Physiol 135:1621-1629.

Yoshida R, Hobo T, Ichimura K, Mizoguchi T, Takahashi F, Aronso J, Ecker JR and Shinozaki K (2002) ABA-activated SnRK2 protein kinase is required for dehydration stress signaling in Arabidopsis. Plant Cell Physiol 43:1473-1483. 
Wang C, Deng P, Chen L, Wang X, Ma H, Hu W, Yao N, Feng Y, Chai R, Yang G, et al. (2013) A wheat WRKY transcription factor TaWRKY10 confers tolerance to multiple abiotic stresses in transgenic tobacco. PloS One 8:e65120.

Wang J, Liu D, Guo X, Yang W, Wang X, Zhan K and Zhang A (2011) Variability of gene expression after polyhaploidization in wheat (Triticum aestivum L.). G3 (Bethesda) $1: 27-33$.

Way H, Chapman S, McIntyre L, Casu R, Xue GP, Manners J and Shorter R (2005) Identification of differentially expressed genes in wheat undergoing gradual water deficit stress using a subtractive hybridisation approach. Plant Sci 168:661-670.

Zhang D, Choi DW, Wanamaker S, Fenton RD, Chin A, Malatrasi M, Turuspekov Y, Walia H, Akhunov ED, Kianian P, et al. (2004) Construction and evaluation of cDNA libraries for large-scale expressed sequence tag sequencing in wheat (Triticum aestivum L.). Genetics 168:595-608.

Zhang H, Cui F and Wang H (2014) Detection of quantitative trait loci (QTLs) for seedling traits and drought tolerance in wheat using three related recombinant inbred line (RIL) populations. Euphytica 196:313-330.

Zhang Z, Liu X, Wang X, Zhou M, Zhou X, Ye X and Wei X (2012) An R2R3 MYB transcription factor in wheat, TaPIMP1, mediates host resistance to Bipolaris sorokiniana and drought stresses through regulation of defense-and stress-related genes. New Phytol 196:1155-1170.

Zhou Y, Gao F, Liu R, Feng J and Li H (2012) De novo sequencing and analysis of root transcriptome using 454 pyrose- quencing to discover putative genes associated with drought tolerance in Ammopiptanthus mongolicus. BMC Genomics 13:266.

\section{Supplementary Material}

The following online material is available for this article: Figure S1 - Gene expression distribution between control and drought-stressed (treated) roots and leaves of the wheat cultivar MGS1 Aliança.

Figure S2 - Correlation of transcript levels between RNAseq and RT-qPCR data.

Figure S3 - Results of the Blast2GO analysis with the 3,987 candidate genes.

Figure S4 - Transcription factor distribution by family.

Table S1 - The set of 4,422 candidate genes identified in root and leaf tissues of the wheat cultivar MGS1 Aliança under drought.

Table S2 - Group of transcripts used in validation by RTqPCR.

Table S3 - Biological pathways activated in wheat drought response (Blast2GO and KEGG analysis)

Table S4 - Details of selected candidate genes.

Associate Editor: Dario Grattapaglia

License information: This is an open-access article distributed under the terms of the Creative Commons Attribution License (type CC-BY), which permits unrestricted use, distribution and reproduction in any medium, provided the original article is properly cited. 